University of New Mexico

UNM Digital Repository

Mathematics and Statistics Faculty and Staff

Publications

Academic Department Resources

$7-2020$

Plithogenic Cognitive Maps in Decision Making

Florentin Smarandache

Nivetha Martin

Follow this and additional works at: https://digitalrepository.unm.edu/math_fsp

Part of the Business Administration, Management, and Operations Commons, Business Analytics

Commons, Logic and Foundations Commons, Other Mathematics Commons, and the Set Theory

Commons 


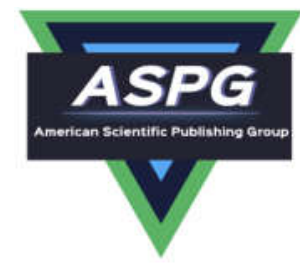

\title{
Plithogenic Cognitive Maps in Decision Making
}

\author{
Nivetha Martin ${ }^{1}$ and Florentin Smarandache ${ }^{2}$ \\ ${ }^{1}$ Department of Mathematics, Arul Anandar College (Autonomous), Karumathur, India, \\ nivetha.martin710@gmail.com \\ 2 Department of Mathematics, University of New Mexico, Gallup, NM 87301,USA, \\ smarand@unm.edu \\ * Correspondence: nivetha.martin710@gmail.com
}

\begin{abstract}
Plithogenic sets introduced by Smarandache (2018) have disclosed new research vistas and this paper introduces the novel concept of plithogenic cognitive maps (PCM) and its applications in decision making. The new approach of defining instantaneous state neutrosophic vector with the confinement of indeterminacy to $(0,1]$ is proposed to quantify the degree of indeterminacy. The resultant vector is obtained by applying instantaneous state vector through the connection matrix together with plithogenic operators comprising the contradiction degrees. The connection matrix is represented as fuzzy matrix and neutrosophic matrix and the resultant vector is determined by applying plithogenic fuzzy operators and plithogenic neutrosophic operators respectively. The obtained results are highly feasible in making the decision as it incorporates the contradiction degree of the conceptual nodes with respect to the dominant node. This research work will certainly pave the way for developing new approaches in decision making using PCM.
\end{abstract}

Keywords: Plithogenic set, cognitive maps, plithogenic cognitive maps, confinement of indeterminacy, plithogenic fuzzy operators, plithogenic neutrosophic operators.

\section{Introduction}

Robert Axelrod [1] developed cognitive maps, a decision making tool primarily used in handling the system of making decisions related to political and social frameworks. A cognitive map is a directed graph with nodes and edges representing the concept variables or factors, and it's causal relationships respectively. The intensity of the relationship between two concepts say $\mathrm{Ci}$ and $\mathrm{Cj}$ is represented by edge weights eij, where eij $\in\{-$ $1,0,1\}$. The value 1 represents the positive influence of $\mathrm{Ci}$ over $\mathrm{Cj} ; 0$ represents no influence and -1 represents negative influence. The causal relationship between the nodes is represented as a connection matrix. Cognitive maps have a wide range of applications in diverse fields. Nakamura et al [2] used cognitive maps in decision support systems; Chaib-draa [3] developed multi agent system model using cognitive maps; Klein et al [4] developed 
cognitive maps in decision makers and other broad spectrum of its applications in student modeling whilst knowledge management are discussed by Alejandro Pena [5]. One of the limitations of cognitive maps is modeling decision making in uncertain environment. The concept of fuzzy sets introduced by Zadeh [6] was integrated with cognitive maps by Kosko [7]. Fuzzy cognitive maps (FCM) introduced by Kosko [7], he handled the aspects of uncertainty and impreciseness. In FCM, the edge weights eij $\in[-1,1]$ and the connection matrix has fuzzy values. The comprehensive nature of FCM has several applications such as but not limited to the pattern recognition see Papakostas et al [8],in the medicine see Abdollah et al [9], in large manufacturing system see Chrysostomos et al [10], in the field of decision making on farming scenarios see Asmaa Mourhir et al [11]. Atannsov [12] introduced intuitionistic fuzzy sets that deal with membership, non-membership and hesitancy values. Elpiniki Papageorgiou[13] extended FCM to Intuitionistic FCM models to apply in medical diagnosis and this gained momentum in the domain of FCM. IFCM are the extension of FCM models, that are highly applied in diverse fields. The connection matrix of iFCM models has intuitionistic values. Hajek et al [14-15] extended iFCM models into interval -valued IFCM for stock index forecasting and supplier selection.

Smarandache [16] introduced neutrosophic sets that deal with truth, indeterminacy and falsity membership functions. Neutrosophic sets are applied in various domain of the natural science. Mohamed Bisher Zeina [17] applied neutrosophic parameters in Erlang Service Queuing Model and developed neutrosophic event-based queuing model. Malath [18]studied the integration of neutrosophic thick function. Salma [19] developed online analytical processing operations via neutrosophic systems. Neutrosophy is also extended to explore new algebraic structures and concepts. Agboola [20] proposed the introduction of neutrogroups and neutrorings, Riad et al [21] constructed neutrosophic crisp semi separation axioms in neutrosophic crisp topological spaces. Necati Olgun [22] discussed refined neutrosophic R-module, Ibrahim [23] explored the concepts of n Refined Neutrosophic Vector Spaces. Mohammad Hamidi [24] discussed Neutro - BCK-algebra. Neutrosophic research is gaining momentum and it has wide spectrum of applications in decision making. Abdel-Baset [25] developed a novel neutrosophic approach in green supplier selection and a novel decision making approach was developed to diagnose heart diseases using neutrosophic sets. Interval - valued neutrosophic sets are also used in decision making. Neutrosophic cognitive maps (NCM) introduced by Vasantha Kandasamy [26] has incorporated the concept of indeterminacy into edge weights. NCMs are also applied to diverse decision making scenarios by many social researchers. NCMs are widely applied to analyze the causal relationship between the concepts of decision making problems. Nivetha et al [27] developed decagonal linguistic neutrosophic FCM to analyze the risk factors of lifestyle diseases. Nivetha et al [28] made a case study on the problems faced by entrepreneurs using NCM.

In NCM models, the influence of one factor over another is represented by either $-1,0,1, \mathrm{I}$, where I represents indeterminacy. Let us consider a decision making problem comprising of five factors and the respective $5 \times 5$ connection matrix has the values $\{-1,0,1, I\}$. The initial state vector $X,[X=(10000)]$ has first of the factors in ON position and other factors in off position. $X$ is passed into connection matrix and the resulting vector $Z,[Z=$ (a1,a2,a3,a4,a5)] is updated using threshold operation by replacing ai by 1 if ai $\geq \mathrm{g}$ and ai by 0 if ai $<\mathrm{g}$, (g is an integer) and ai by $\mathrm{I}$, if ai is not an integer. The process is repeated until two updated resultant vectors obtained are 
same, which is called as the fixed point or limit cycle. The process ends when the fixed point is obtained. In this

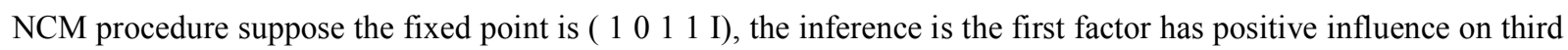
and fourth factors, no impact on second factor and the fifth factor is indeterminant to it. The existence of indeterminacy in the connection matrix and the fixed point does not give us the complete picture of the decision making, but if indeterminacy is quantified then the decision making will be feasible. To make so, the approach of indeterminacy confinement is introduced in this research work. As the connection matrix is based on expert's opinion, the indeterminacy can also be confined to $(0,1]$ based on the expert's opinion. Also in the instantaneous vector any of the factors are in $\mathrm{ON}$ position or combination of factors are in ON position say, $\mathrm{X}=\left(\begin{array}{llll}1 & 0 & 1 & 01\end{array}\right)$ to see the combined effect of the factors. In this article the factors are kept in indeterminate position and it is confined to give a numerical value. This is a new kind of approach in neutrosophic cognitive maps and the NCMs of this kind can be labeled as novel neutrosophic cognitive maps (NNCM).

The NCM and NNCM can also be extended to plithogenic cognitive maps (PCM). Plithogenic sets introduced by Smarandache [29] are the generalization of crisp sets, fuzzy sets, intuitionistic fuzzy sets and neutrosophic sets. The membership values are mainly used to quantify the qualitative aspects. This principle of quantification of qualitative aspects is used as the underlying principle in the construction of plithogenic sets. The degree of appurtenance and the contradiction degree are the two distinctive aspects of plithogenic sets. The concept of plithogeny is extended to plithogenic hypersoft sets by Smarandache [30]. Plithogenic sets are widely used in decision making. Shazia Rana et al [31] extended plithogenic fuzzy hypersoft set to plithogenic fuzzy whole hypersoft set and developed plithogenic ranking model. Nivetha and Smarandache [32] developed concentric plithogenic hypergraphs. Smarandache [33] developed plithogenic n super hypergraph and a novel decision making approach is proposed by Smarandache and Nivetha [34]. Abdel - Baset [35] framed a hybrid plithogenic decisionmaking approach with quality function deployment for selecting supply chain sustainability. The compatibility of the plithogenic sets motivated us to incorporate the concept of plithogeny to coginitve maps.

This research work proposes the approach of integrating plithogeny to cognitive maps to develop PCM models as the extension of NNCM, NCM, IFCM and FCM. The PCM model follows the underlying methodology of FCM but it incorporates contradiction degree to the factors of the decision making problem. If any of the factors is in $\mathrm{ON}$ position, then it becomes the dominant factor and the contradiction degree of the dominant factor with respect to other factors is considered. The instantaneous vector is passed into connection matric and the resultant vector is obtained by applying plithogenic operators. The resultant vector is updated by using the conventional threshold function. PCM models are classified as cognitive maps if the connection matrix is crisp; fuzzy cognitive maps if the connection matrix has fuzzy values; intuitionistic fuzzy cognitive maps if the connection matrix has intuitionistic values and neutrosophic cognitive maps if the connection matrix has neutrosophic values. Thus the proposed PCM models are the generalization of the earlier forms of FCM models. The incorporation of the contradiction degrees will certainly give us new insights in decision making. 
The paper is organized as follows: section 2 presents the outlook of PCM; section 3 consists of the methodology of PCM; section 4 comprises of application of PCM in decision making; section 5 discusses the results and concludes the work.

\section{Plithogenic Cognitive Maps}

A plithogenic cognitive map is a directed graph consisting of nodes and edges representing the concepts and its causal relationship respectively. The contradiction degree of the nodes with respect to the dominant node is determining the fixed point.

Let $\mathrm{P}_{1}, \mathrm{P}_{2}, . . \mathrm{P}_{\mathrm{n}}$ denotes $\mathrm{n}$ nodes of PCM. The directed edge from $\mathrm{P}_{\mathrm{i}}$ to $\mathrm{P}_{\mathrm{j}}$ represents the association between the two nodes and the edge weights illustrate the intensity of the association between the nodes. If the edge weight $\mathrm{e}_{\mathrm{ij}} \in\{-1,0,1\}$ then it is plithogenic crisp cognitive maps; if $\mathrm{e}_{\mathrm{ij}} \in[-1,1]$ then it is plithogenic fuzzy cognitive maps; if $\mathrm{e}_{\mathrm{ij}} \in \rho\left([0,1]^{2}\right)$ then it is plithogenic intuitionistic cognitive maps, if $\mathrm{e}_{\mathrm{ij}} \in \rho\left([0,1]^{3}\right)$ then it is plithogenic neutrosophic cognitive maps. Plithogenic connection matrix or adjacency matrix $P(E)=\left(e_{i j}\right)$ represents the relation between the nodes. An instantaneous state vector in PCM of the form $A=\left(a_{1}, a_{2}, . . a_{n}\right)$ represents the ON-OFF-indeterminate position of the node at an instant of time. If $a_{i}=1$ refer to (ON state); $a_{i}=0$ refer to (OFF state) and $a_{i}=I$ means (Indeterminate state). In PCM, the indeterminate state $\mathrm{I}$ is confined to a value belonging to $(0,1]$, which is the extension of NCM.

Let P1,P2,P3 be three nodes of PCM. Let P1 be in ON position and P2, P3 be in off state, then the node P1 is considered to be dominant. The contradiction degrees of other nodes with respect to dominant node are

\begin{tabular}{|l|l|l|}
\hline P1 & P2 & P3 \\
\hline 0 & $1 / 3$ & $2 / 3$ \\
\hline
\end{tabular}

The contradiction degree represents the extent of distinctiveness between the two concepts . The value $1 / 3$ and $2 / 3$ is assigned to P2 or P3 based on the perception of decision makers who have choosen the factors of PCM.

The instantaneous vector $\mathrm{X}=\left(\begin{array}{lll}1 & 0 & 0\end{array}\right)$ is passed into $\mathrm{P}(\mathrm{E})$ and the vector which is obtained by applying plithogenic operators is $\mathrm{Y}$. The assumed threshold operation is applied to $\mathrm{Y}$ and the resultant vector $\mathrm{G}$ is obtained. The recurrence of passing the resultant vector $\mathrm{G}$ to $\mathrm{P}(\mathrm{E})$ if results in repetition of resultant vectors then the limit cycle of the PCM is obtained and the resultant vector is called as fixed point.

\section{Methodology of Plithogenic Cognitive Maps}

This section presents the algorithm of obtaining the limit cycle of PCM.

Step 1: The factors $\mathrm{P}_{1}, \mathrm{P}_{2}, . . \mathrm{P}_{\mathrm{n}}$ or the concepts of the decision making problem are decided based on the expert's opinion. 
Step 2: The plithogenic connection matrix $\mathrm{P}(\mathrm{E})$ of dimension $\mathrm{n}$ (the number of concepts) is obtained from the causal relationship between the concepts.

Step 3: The edge weight $\mathrm{e}_{\mathrm{ij}}$ may belong to $\{1,0,1\},[-1,1], \rho\left([0,1]^{2}\right), \rho\left([0,1]^{3}\right)$. The nature of the edge weights determines the type of plithogenic cognitive maps.

Step 4: To determine the effect of one concept say $\mathrm{P} 1$, is kept in $\mathrm{ON}$ position and the contradiction degree with respect to other concepts are determined.

Step 5: The instantaneous state vector $X=\left(\begin{array}{llllll}1 & 0 & 0 & 0 & 0 & \ldots\end{array}\right)$ is passed into connection matrix and by applying the plithogenic operators, a resultant vector is obtained, and updated by applying the threshold operation by assigning 1 to the values $\left(a_{i}\right)$ greater than $k$, 0 to the values $\left(a_{i}\right)$ lesser than $k$, where $k-a$ is a suitable positive integer. In this proposed approach the on position of the concepts is threshold with 1 and the indeterminate position of the concepts will be confined with the value $\mathrm{C}$. The value 0 is assigned to the values lesser than 1 and the value 1 is assigned to the values greater than 1 .

The plithogenic operators are defined as

$\mathrm{a} \wedge_{\mathrm{p}} \mathrm{b}=(1-\mathrm{c}) \cdot\left[\mathrm{a} \wedge_{\mathrm{F}} \mathrm{b}\right]+\mathrm{c} \cdot\left[\mathrm{a} \vee_{\mathrm{F}} \mathrm{b}\right]$, where $\mathrm{c}$ represents contradiction degree, $a \wedge_{F} b$ is the $\mathrm{t}_{\text {norm }}$ defined by ab and $a \vee_{F} b$ is the $\mathrm{t}_{\text {conorm }}$ defined by $\mathrm{a}+\mathrm{b}-\mathrm{ab}$

The plithogenic new neutrosophic operators are defined as

$$
\begin{aligned}
& a \wedge_{p} b=\prec a_{1} \wedge_{p} b_{1}, \frac{1}{2}\left[\left(a_{2} \wedge_{p} b_{2}\right)+\left(a_{2} \vee_{p} b_{2}\right)\right], a_{3} \vee_{p} b_{3} \succ \\
& \text { where } a=\left(a_{1}, a_{2}, a_{3}\right) \text { and } b=\left(b_{1}, b_{2}, b_{3}\right), a \vee_{p} b=(1-c) \cdot\left[a \vee_{p} b\right]+c \cdot\left[a \wedge_{p} b\right]
\end{aligned}
$$

Step 6 : The updated vector is passed into $\mathrm{P}(\mathrm{E})$ and the process is repeated until the fixed point is arrived. The fixed point is the limit cycle of PCM.

\section{Application of Plithogenic Cognitive Maps in Decision Making}

This section presents the application of plithogenic cognitive maps in decision making. Let us consider a decision making environment where the expert's opinion is constructed to promote the farming sectors to a progressive phase with their suggestive strategies. The following proposed strategies of the experts are taken as the nodes of the PCM.

P1 Encouraging the reverse migration by helping the socially mobilized groups with credit

flow.

P2 Supporting vulnerable farming areas with community driven approach

P3 Promoting Farmer's Productive Organizations as transformative agents

P4 Perpetuating gender equalities to create new opportunities for women

P5 Effective use of modern ICT to connect farmers with extension, market and continuous learning 
The causal association between the concepts is represented as linguistic variables and it is quantified by triangular fuzzy numbers and the kind of PCM is plithogenic fuzzy cognitive map which is used to determine the fixed point of the dynamical system.

The plithogenic fuzzy connection matrix with linguistic variables is presented as below

$\left(\begin{array}{llllll} & \mathrm{P}_{1} & \mathrm{P}_{2} & \mathrm{P}_{3} & \mathrm{P}_{4} & \mathrm{P}_{5} \\ \mathrm{P}_{1} & 0 & \mathrm{M} & \mathrm{M} & \mathrm{L} & \mathrm{L} \\ \mathrm{P}_{2} & \mathrm{~L} & 0 & \mathrm{H} & \mathrm{M} & \mathrm{L} \\ \mathrm{P}_{3} & \mathrm{H} & \mathrm{H} & 0 & \mathrm{M} & \mathrm{H} \\ \mathrm{P}_{4} & \mathrm{M} & \mathrm{M} & \mathrm{L} & 0 & \mathrm{M} \\ \mathrm{P}_{5} & \mathrm{H} & \mathrm{H} & \mathrm{VH} & \mathrm{M} & 0\end{array}\right)$

The linguistic variables are quantified by using triangular fuzzy numbers as in Table 4.1

Table 4.1 Quantification of Linguistic variable

\begin{tabular}{|c|c|c|}
\hline Linguistic Variable & Triangle Fuzzy Number & Crisp value \\
\hline Very Low & $(0,0.1,0.2)$ & 0.1 \\
\hline Low & $(0.2,0.3,0.4)$ & 0.3 \\
\hline Medium & $(0.4,0.5,0.6)$ & 0.5 \\
\hline High & $(0.6,0.7,0.8)$ & 0.7 \\
\hline Very High & $(0.8,0.9,1)$ & 0.9 \\
\hline
\end{tabular}

The modified plithogenic fuzzy connection matrix $\mathrm{P}(\mathrm{E})$ is

$\left(\begin{array}{llllll} & \mathrm{P} 1 & \mathrm{P} 2 & \mathrm{P} 3 & \mathrm{P} 4 & \mathrm{P} 5 \\ \mathrm{P} 1 & 0 & 0.5 & 0.5 & 0.3 & 0.3 \\ \mathrm{P} 2 & 0.3 & 0 & 0.7 & 0.5 & 0.3 \\ \text { P3 } & 0.7 & 0.7 & 0 & 0.5 & 0.7 \\ \text { P4 } & 0.5 & 0.5 & 0.3 & 0 & 0.5 \\ \text { P5 } & 0.7 & 0.7 & 0.9 & 0.5 & 0\end{array}\right)$

The graphical representation of the causal association between the concepts are represented in Fig.4.1 


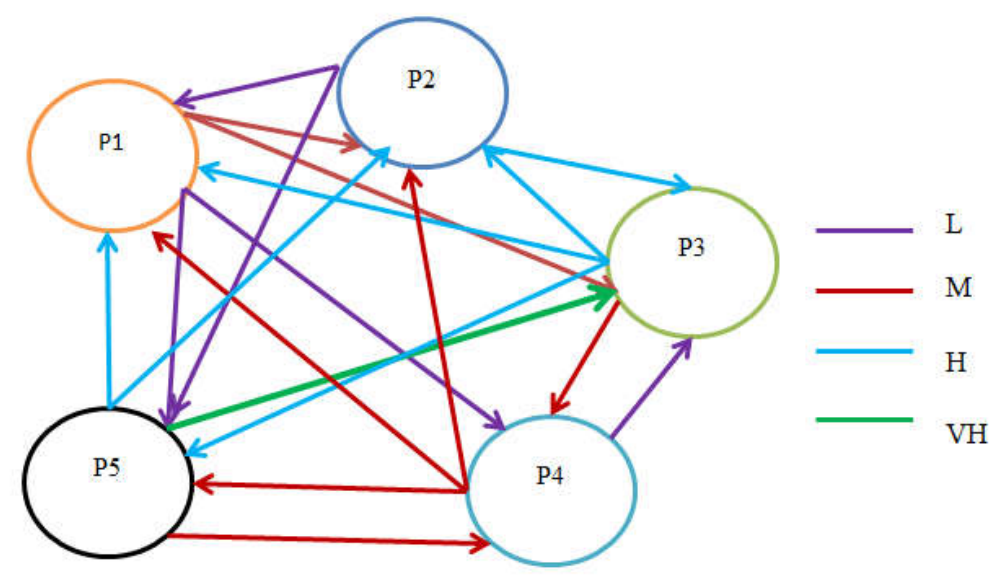

Fig.4.1 Graphical representation of the causal relationship

\section{Case (i) Conventional FCM [7]}

Let us consider the conventional approach of FCM without the incorporation of contradiction degree. Let $\mathrm{X}=\left(\begin{array}{lll}1 & 0 & 0\end{array}\right.$ $00)$

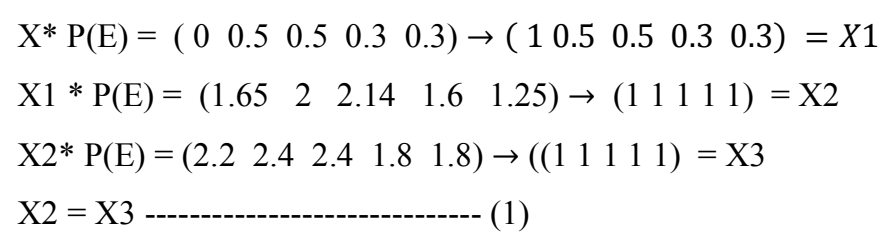

\section{Case (ii) Plithogenic Fuzzy FCM with ON/OFF state of vectors}

Let us consider the concept $\mathrm{P} 1$ to be in $\mathrm{ON}$ position and other factors in off position. The contradiction degrees of the dominant node with respect to other nodes are

\begin{tabular}{|l|l|l|l|l|}
\hline P1 & P2 & P3 & P4 & P5 \\
\hline 0 & $1 / 5$ & $2 / 5$ & $3 / 5$ & $4 / 5$ \\
\hline
\end{tabular}

Let us consider the instantaneous state vector as $\mathrm{X}=\left(\begin{array}{lllll}1 & 0 & 0 & 0 & 0\end{array}\right)$

$X * p P(E)=Y$, where $Y=(a b c d e)$

$\mathrm{a}=\operatorname{Max}[1 \wedge \mathrm{p} 0,0 \wedge \mathrm{p} 0.3,0 \wedge \mathrm{p} 0.7,0 \wedge \mathrm{p} 0.5,0 \wedge \mathrm{p} 0.7]$

$\mathrm{b}=\operatorname{Max}[1 \wedge \mathrm{p} 0.5,0 \wedge \mathrm{p} 0,0 \wedge \mathrm{p} 0.7,0 \wedge \mathrm{p} 0.5,0 \wedge \mathrm{p} 0.7]$

$\mathrm{c}=\operatorname{Max}[1 \wedge \mathrm{p} 0.5,0 \wedge \mathrm{p} 0.7,0 \wedge \mathrm{p} 0,0 \wedge \mathrm{p} 0.3,0 \wedge \mathrm{p} 0.9]$

$\mathrm{d}=\operatorname{Max}[1 \wedge \mathrm{p} 0.3,0 \wedge \mathrm{p} 0.5,0 \wedge \mathrm{p} 0.5,0 \wedge \mathrm{p} 0,0 \wedge \mathrm{p} 0.5]$

$\mathrm{e}=\operatorname{Max}[1 \wedge \mathrm{p} 0.3,0 \wedge \mathrm{p} 0.3,0 \wedge \mathrm{p} 0.7,0 \wedge \mathrm{p} 0.5,0 \wedge \mathrm{p} 0]$

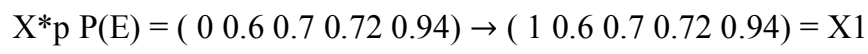

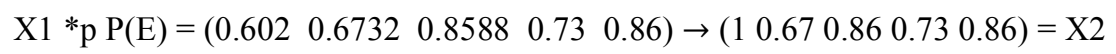




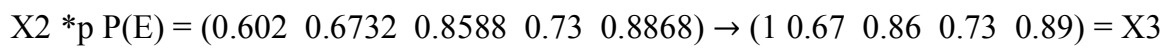

$$
\begin{aligned}
& \mathrm{X} 3 * \mathrm{p} P(\mathrm{E})=\left(\begin{array}{lllll}
0.623 & 0.6918 & 0.8762 & 0.745 & 0.8868
\end{array}\right) \rightarrow\left(\begin{array}{lllll}
1 & 0.69 & 0.88 & 0.75 & 0.89
\end{array}\right)=\mathrm{X} 4
\end{aligned}
$$

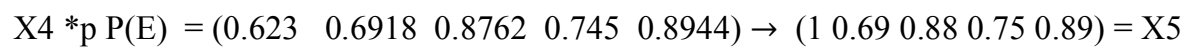

$\mathrm{X} 4=\mathrm{X} 5$

\section{Case (iii) Plithogenic Fuzzy FCM with ON/OFF and confined indeterminate $I_{C}$ state of vectors}

Let us consider the concept $\mathrm{P} 1$ to be in $\mathrm{ON}$ position, $\mathrm{P} 2$ be in indeterminate state and other factors in off position. The indeterminate state of the vector here reflects the impact on the concept P2.The contradiction degrees of the dominant node with respect to other nodes are considered as the same.

Let us consider the instantaneous state vector as $X=\left(\begin{array}{llll}1 & I_{C} & 0 & 0\end{array}\right), C=0.25$, the value of indeterminacy is 0.25 . i.e $X$ $=\left(\begin{array}{lllll}1 & 0.25 & 0 & 0 & 0\end{array}\right)$

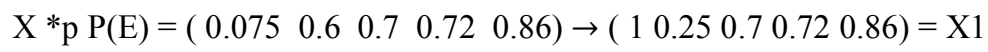

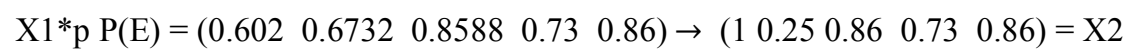

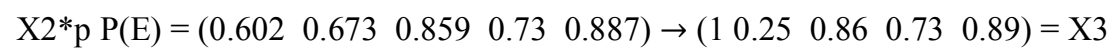

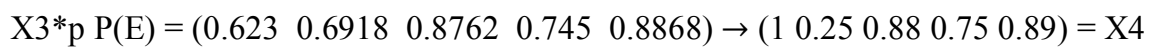

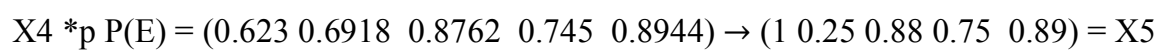

$$
\begin{aligned}
& \mathrm{X} 4=\mathrm{X} 5
\end{aligned}
$$

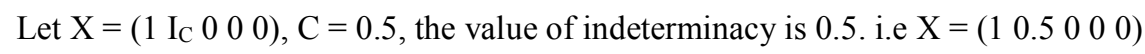

The fixed point is ( 10.250 .880 .750 .89 )

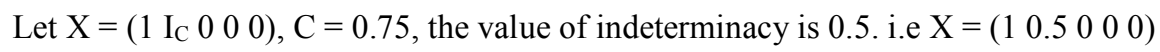

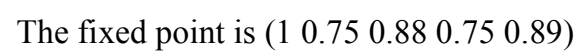

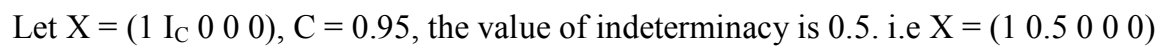

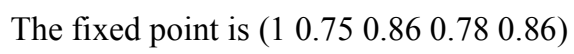

Eq. (1) states that the concept P1 has influence on the other concepts, but Eq. (2) states the extent of influence of the concept P1 on other concepts which is the added advantage of using contradiction degree. The confined indeterminate state for various values of $\mathrm{c}$ results in different fixed points. The confinement of indeterminacy to the values $\mathrm{C}=0.25,0.5,0.75$ have same impact on other factors and also it produce the same effect as $\mathrm{P} 2$ concept in OFF state, but as the value of indeterminacy is enhanced, slight variation in the impact are found in Eq. (6). This shows that the OFF state and the indeterminate state of concept $\mathrm{P} 2$, when the concept $\mathrm{P} 1$ being in ON position produce no much difference.

\section{Case (iv). Plithogenic Neutrosophic FCM with new neutrosophic state.}

The new neutrosophic instantaneous state vector is of the form $\left(\left(T_{\mathrm{P} 1}, \mathrm{I}_{\mathrm{P} 1}, \mathrm{~F}_{\mathrm{P} 1}\right), 0,0,0,0\right)$, where the truth $\left(\mathrm{T}_{\mathrm{P} 1}\right)$, indeterminacy $\left(\mathrm{I}_{\mathrm{P} 1}\right)$ and falsity $\left(\mathrm{F}_{\mathrm{P} 1}\right)$ of the concept $\mathrm{P} 1$ to be in $\mathrm{ON}$ position is expressed. This representation of the ON position of the vector is highly a pragmatic representation. If $\mathrm{I}_{\mathrm{P} 1}$ and $\mathrm{F}_{\mathrm{P} 1}$ are zero then the concept P1 is highly certain to be in ON position. The indeterminate and off state of the concept P1 can be expressed by keeping the values of $I_{P 1}$ and $F_{P 1}$ to 1 and keeping the other respective set of value to be zero. 
The new neutrosophic state vector $\left(\mathrm{X}_{\mathrm{N}}\right)$ when the On state of the concept P1 is considered. $((1,0,0)(0,1,1)$ $(0,1,1)(0,1,1)(0,1,1))$. The plithogenic neutrosophic matrix $\mathrm{P}_{\mathrm{N}}(\mathrm{E})$ is

$\left.\begin{array}{llllll} & \text { P1 } & \text { P2 } & \text { P3 } & \text { P4 } & \text { P5 } \\ \text { P1 } & (0,1,1) & (0.6,0.3,0.4) & (0.6,0.3,0.4) & (0.3,0.4,0.7) & (0.3,0.4,0.7) \\ \text { P2 } & (0.3,0.4,0.7) & (0,1,1) & (0.7,0.2,0.2) & (0.6,0.3,0.4) & (0.3,0.4,0.7) \\ \text { P3 } & (0.7,0.2,0.2) & (0.7,0.2,0.2) & (0,1,1) & (0.6,0.3,0.4) & (0.7,0.2,0.2) \\ \text { P4 } & (0.6,0.3,0.4) & (0.6,0.3,0.4) & (0.3,0.4,0.7) & (0,1,1) & (0.6,0.3,0.4) \\ \text { P5 } & (0.7,0.2,0.2) & (0.7,0.2,0.2) & (0.9,0.1,0.1) & (0.6,0.3,0.4) & (0,1,1)\end{array}\right)$

The plithogenic representation of the causal relationship between the concepts is presented in Fig.4.2. The positive sign indicates the positive impacts of the concepts, and it is represented as neutrosophic values in $\mathrm{P}_{\mathrm{N}}(\mathrm{E})$.

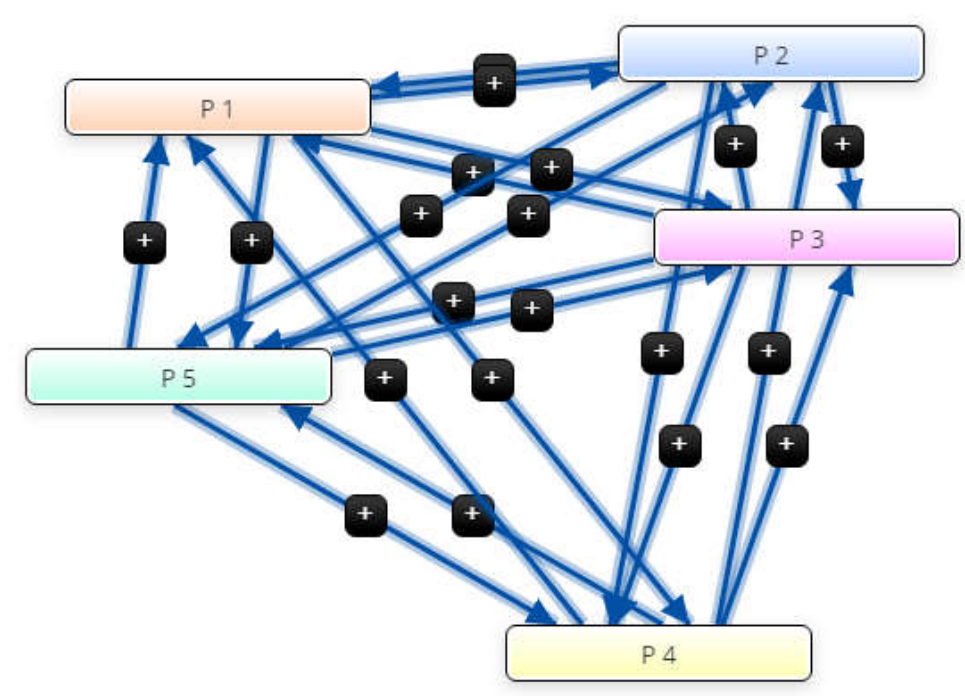

Fig.4.2 Representation of Plithogenic association between the concepts

The plithogenic operators are used to obtain the resultant vector.

Let $\mathrm{X}_{\mathrm{N}}=((1,0,0),(0,1,1),(0,1,1),(0,1,1),(0,1,1))$

$\mathrm{X}_{\mathrm{N}} * \mathrm{p} \mathrm{P}_{\mathrm{N}}(\mathrm{E})=((0,0,0)(0.68,0.19,0),(0.76,0.18,0)(0.72,0.26,0)(0.86,0.23,0))$

$\rightarrow((1,0,0)(0.68,0.19,0),(0.76,0.18,0)(0.72,0.26,0)(0.86,0.23,0))=\mathrm{X}_{\mathrm{N} 1}$ 
$\mathrm{X}_{\mathrm{N} 1} * \mathrm{p} \mathrm{P}_{\mathrm{N}}(\mathrm{E})=((0.602,0.118,0)(0.68,0.1288,0.1088)(0.76,0.1396,0.1632)(0.84,0.1504,0.1632)(0.920 .16$ $0.1088)) \rightarrow((1,0,0)(0.68,0.1288,0.1088)(0.76,0.1396,0.1632)(0.84,0.1504,0.1632)(0.920 .160 .1088))=X_{\mathrm{N} 2}$

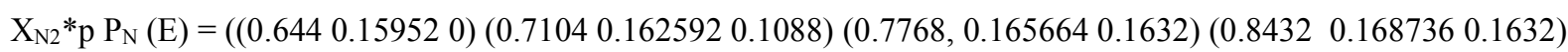

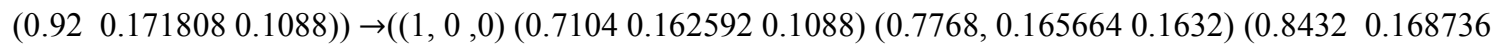
$0.1632)\left(\begin{array}{lll}0.92 & 0.1718080 .1088)\end{array}\right)=\mathrm{X}_{\mathrm{N} 3}$ $\mathrm{X}_{\mathrm{N} 3} * \mathrm{p} \mathrm{P}_{\mathrm{N}}(\mathrm{E})=\left(\begin{array}{llll}(0.644 & 0.1607008 & 0\end{array}\right)\left(\begin{array}{llll}0.7104 & 0.16448128 & 0.113664\end{array}\right)\left(\begin{array}{llll}0.7768 & 0.16826176 & 0.113664\end{array}\right)\left(\begin{array}{ll}0.7768 \\ 0\end{array}\right.$ $\left.\begin{array}{llllll}0.16826176 & 0.170496\end{array}\right)\left(\begin{array}{lllll}0.8432 & 0.17204224 & 0.170496\end{array}\right)\left(\begin{array}{lll}0.92 & 0.17582272 & 0.113664\end{array}\right) \rightarrow\left(\begin{array}{lll}(1,0,0) & (0.710 & 0.164\end{array}\right.$ $\left.0.114)\left(\begin{array}{lllll}0.777 & 0.168 & 0.114\end{array}\right)\left(\begin{array}{llll}0.777 & 0.168 & 0.170\end{array}\right)\left(\begin{array}{lll}0.843 & 0.172 & 0.170\end{array}\right)\left(\begin{array}{lll}0.92 & 0.176 & 0.114\end{array}\right)\right)=\mathrm{X}_{\mathrm{N} 4}$

By repeating in the same fashion,

$\mathrm{X}_{\mathrm{N} 5}=((1,0,0)(0.71,0.167,0.114)(0.777,0.171,0.17)(0.843,0.174,0.17)(0.91,0.178,0.114)$

$\mathrm{X}_{\mathrm{N} 6}=((1,0,0)(0.71,0.167,0.114)(0.777,0.171,0.17)(0.843,0.174,0.17)(0.91,0.178,0.114)$

$\mathrm{X}_{\mathrm{N} 5}=\mathrm{X}_{\mathrm{N} 6}$

Thus the neutrosophic impact of the concept P1 on other factors is determined. The various kinds of plithogenic cognitive maps are discussed in different cases and in each case, the impact of the concept P1 over the other concepts is determined. In section 4 various cases are discussed and the differences between cognitive maps (CM), fuzzy cognitive maps (FCM), intuitionistic cognitive maps(IFCM), neutrosophic cognitive maps(NCM) and plithogenic cognitive maps (PCM) based on edge weights $\left(\mathrm{e}_{\mathrm{ij}}\right)$ are presented in Table 4.2.

Table 4.2. Differences beteween CM, FCM, IFCM,NCM and PCM

\begin{tabular}{|l|l|}
\hline Cognitive Maps & $\begin{array}{l}\mathrm{e}_{\mathrm{ij}} \in\{-1,0,1\} \text { with no contradiction degree } \\
\text { between the concepts }\end{array}$ \\
\hline Fuzzy cognitive maps & $\begin{array}{l}\mathrm{e}_{\mathrm{ij}} \in[-1,1] \text { with no contradiction degree between } \\
\text { the concepts }\end{array}$ \\
\hline Intuitionistic cognitive maps & $\begin{array}{l}\mathrm{e}_{\mathrm{ij}}=(\mu, v) \text { where } \mu, \text { the membership value and } v, \\
\text { the non-membership value with no contradiction } \\
\text { degree between the concepts }\end{array}$ \\
\hline Neutrosophic Cognitive Maps & $\begin{array}{l}\mathrm{e}_{\mathrm{ij}} \in\{-1,0,1, \mathrm{I}\} \text { with no contradiction degree } \\
\text { between the concepts }\end{array}$ \\
\hline Plithogenic Cognitive Maps & $\begin{array}{l}\mathrm{e}_{\mathrm{ij}} \in\{-1,0,1\} \text { or } \mathrm{e}_{\mathrm{ij}} \in[-1,1] \text { or } \mathrm{e}_{\mathrm{ij}} \in \rho\left([0,1]^{2}\right) \text { or } \mathrm{e}_{\mathrm{ij}} \in \\
\rho\left([0,1]^{3}\right) \text { with contradiction degree between the } \\
\text { concepts }\end{array}$ \\
\hline
\end{tabular}

\section{Conclusion}

This research work proposes the concept of plithogenic cognitive maps and new neutrosophic maps. The integration of contradiction degree with the plithogenic operators is applied to determine the resultant vector. Several kinds of plithogenic cognitive maps are discussed in this article and it is validated with applications in decision making. The proposed plithogenic cognitive maps can be applied in decision making scenario. The state of 
indeterminacy of the concept is quantified by various confinement values which will certainly assist in making optimal decisions. Plithogenic cognitive maps can be also developed to various representations based on the characterisation of the decision making environment. PCM decision making models can be extended to intervalvalued plithogenic cognitive maps and also it can be integrated to multi criteria decision making. The association between the concepts of decision making can be represented in terms of plithogenic hypersoft set. Plithogenic hypergraph can also be integrated with plithogenic cognitive maps to formulate novel and feasible decision making models.

\section{References}

[1] Axelrod, R., Structure of Decision: The Cognitive Maps of Political Elites. Princeton,1976.

[2] Nakamura, K., S. Iwai and T. Sawaragi., "Decision Support Using Causation Knowledge Base", J. IEEE Transactions on Systems, Man and Cybernetics, Vol.12, pp.765-777,1982.

[3] Chaib-draa, B., "Causal Maps: Theory, Implementation, and Practical Applications in Multiagent Environments”, J. IEEE Transactions on Knowledge and Data Engineering, Vol. 14, 2002.

[4] Klein, J.L., D.F. Cooper, “Cognitive Maps Decision Markers in a Complex Game”, J. of Operational Research Soc., Vol.2, pp -377-393,1982.

[5] Alejandro Pena1.,Humberto Sossa., Agustin Gutierrez., "Cognitive Maps: an Overview and their Application for Student Modeling”, Computacion y Sistemas Vol. 10 No. 3, pp -230-250, 2007.

[6] Zadeh, L. A. "Fuzzy set”, Inform and Control 8, 338-353,1965.

[7] Kosko, B., Fuzzy Cognitive Maps. Int. J. of Man-Machine Studies, V. 24, 1986, 65-75.

[8] Papakostas, G. A. , Boutalis, Y. S., Koulouriotis, D. E. ,Mertzios, B. G., "Fuzzy cognitive maps for pattern recognition applications", International Journal of Pattern Recognition and Artificial IntelligenceVol. 22, No. 08, pp. 1461-1486,2008.

[9] Abdollah Amirkhania.,Elpiniki I.Papageorgioub.,AkramMohsenia.,Mohammad R.Mosavia., “A review of fuzzy cognitive maps in medicine: Taxonomy, methods, and applications", Computer Methods and Programs in Biomedicine,Vol.142, pp - 129-145,2017.

[10] Chrysostomos ,D.,StyliosPeter P.Groumpos, “Application of Fuzzy Cognitive Maps in Large Manufacturing Systems", IFAC Proceedings Volumes, Vol. 31, pp-521-526,1998.

[11] Asmaa Mourhir.,Elpiniki I Papageorgiou., Konstantinos Nikolaos Kokkinos.,Tajje-eddine Rachidi., "Exploring Precision Farming Scenarios Using Fuzzy Cognitive Maps”, Sustainability, Vol.9,pp-1-23,2017.

[12] Atanassov, K.T. “Intuitionistic fuzzy sets“. Fuzzy Sets Syst. 20, 87-96,1983.

[13] Elpiniki I Papageorgiou.,Dimitris Iakovidis., “Intuitionistic Fuzzy Cognitive Maps”, IEEE Transactions on Fuzzy Systems. Vol 21, pp -342-354,2013. 
[14] Hajek.P., Prochazka,O., Froelich,W., "Interval-valued intuitionistic fuzzy cognitive maps for stock index forecasting," 2018 IEEE Conference on Evolving and Adaptive Intelligent Systems (EAIS), Rhodes, 2018, pp. 1-7, doi: 10.1109/EAIS.2018.8397170.

[15] Hajek.P., Prochazka,O., "Interval-valued intuitionistic fuzzy cognitive maps for supplier selection", Intelligent Decision Technologies 2017: Proceedings of the 9th KES International Conference on Intelligent Decision Technologies (KES-IDT 2017) - Part I, pp. 207-217, 2018.

[16]Smarandache,F.,'Neutrosophic set, a generalization of the Intuitionistic Fuzzy Sets", International Journal of Pure and Applied Mathematics, Vol.24,pp-, 287-297,2005.

[17] Mohamed Bisher Zeina., "Erlang Service Queueing Model with Neutrosophic Parameters", International Journal of Neutrosophic Science, Vol.6,pp- 106-112,2020.

[18] Malath F. Alaswad., “A Study of the Integration of Neutrosophic Thick Function”, International Journal of Neutrosophic Science, Vol.6,pp- 97-105,2020.

[19] Salama, A. A., Bondok Henawy, M.S, Rafif Alhabib, “Online Analytical Processing Operations via Neutrosophic Systems”, International Journal of Neutrosophic Science, Vol.8,pp- 87-109,2020.

[20] Agboola A.A.A., "Introduction to Neutro Rings", ”, International Journal of Neutrosophic Science, Vol.7,pp$62-73,2020$.

[21] Riad .K. Al-Hamido , Luai Salha, Taleb Gharibah, "Neutrosophic Crisp Semi Separation Axioms In Neutrosophic Crisp Topological Spaces”, International Journal of Neutrosophic Science, Vol.6,pp- 32-40,2020.

[22] Necati Olgun., Ahmed Hatip., “On Refined Neutrosophic R-module”, International Journal of Neutrosophic Science, Vol.7,pp- 87-96,2020.

[23] Ibrahim, M.A.,Agboola, A.A.A. , Badmus, B.S.,Akinleye, S.A., "n Refined Neutrosophic Vector Spaces", International Journal of Neutrosophic Science, Vol.7,pp- 97-109,2020.

[24] Mohammad Hamidi, Florentin Smarandache, "NEUTRO-BCK-algebra", International Journal of Neutrosophic Science, Vol.8,pp- 110-117,2020.

[25] Abdel-Baset, M., Chang, V., Gamal, A. Evaluation of the green supply chain management practices: A novel neutrosophic approach. Computers in Industry,Vol. 108,pp- 210-220,2019.

[26]Vasantha Kandasamy,W. B. ,Florentin Smarandache, "Fuzzy Cognitive Maps and Neutrosophic Cognitive Maps", Xiquan Publishers, Phoenix, 2003.

[27] Nivetha Martin., Aleeswari.A., Lilly Merline,W., "Risk Factors of Lifestyle Diseases - Analysis by Decagonal Linguistic Neutrosophic Fuzzy Cognitive Map”, Materials Today: Proceedings,Vol. 24, pp-1939-1943,2020.

[28]Nivetha Martin., Lilly Merline,W., "A Case Study on the problems faced by the Entrepreneurs of Karumathur in Madurai District”, Global Journal of Finance and Management, Vol. 9, pp. 23-28,2017.

[29]Smarandache, F. Plithogeny, Plithogenic Set, Logic, Probability, and Statistics. 2018, arXiv preprint arXiv:1808.03948.

[30]Smarandache, F. Extension of Soft set to Hypersoft Set, and then to Plithogenic Hypersoft Set, Neutrosophic set and Systems, Vol.22, pp-68-70.,2018. 
[31] Shazia Rana ., Madiha Qayyum.,Muhammad Saeed., Florentin Smarandache ., Bakhtawar Ali Khan., "Plithogenic Fuzzy Whole Hypersoft Set, Construction of Operators and their Application in Frequency Matrix Multi Attribute Decision Making Technique", Neutrosophic Sets and Systems, Vol 28, pp.34-50,2019.

[32] Martin, Nivetha and Florentin Smarandache. "Concentric Plithogenic Hypergraph based on Plithogenic Hypersoft sets - A Novel Outlook." Neutrosophic Sets and Systems Vol.33, pp-78-91,2020.

[33] Smarandache, Florentin., "Extension of HyperGraph to n-SuperHyperGraph and to Plithogenic nSuperHyperGraph, and Extension of HyperAlgebra to n-ary (Classical-/Neutro-/Anti-)HyperAlgebra" Neutrosophic Sets and Systems, Vol 33, pp.290-296, 2020.

[34] Florentin Smarandache., Nivetha Martin., "Plithogenic n- Super Hypergraph in Novel Multi - Attribute Decision Making”, International Journal of Neutrosophic Science, Vol.7,pp-8-30,2020.

[35] Abdel-Basset, M., Mohamed, R., Zaied, A. E. N. H., \& Smarandache, F. A hybrid plithogenic decision-making approach with quality function deployment for selecting supply chain sustainability metrics. Symmetry, Vol.11,903,2019. 